\title{
Clarifying the impacts of professors' narcissism variables on effective performance
}

\author{
${\text { Gholamreza Jandaghi }{ }^{1, a} \text {, Samira Fakheri Kozekanan }}^{2, b}$, Ali Pirannejad ${ }^{3}$ \\ ${ }^{1}$ Faculty of Management and Accounting, Farabi Campus, University of Tehran, Tehran, Iran \\ ${ }^{2}$ University of Tehran, Tehran, Iran \\ ${ }^{3}$ Public Administration Department, University of Tehran, Tehran, Iran \\ a,bE-mail address: jandaghi@ut.ac.ir , sfakherik@ut.ac.ir
}

\begin{abstract}
Universities are one of the major factors in improvement of countries and their performance has a key role in scientific enhancement in national and international level. There is an effect in top universities to join first 500 universities in global level. Iran is going to obtain the first scientific ranking the region at 1404. The main goal of this article is recognizing the impact of narcissism on faculty member's performance. Obtaining the first rank is depends on faculty members'effort. In this research we investigate the narcissism in faculty members that influence learning and eventually performance. We took advantages the quantitative method and used survey to collect the data among 300 faculty members. The results exhibit that narcissism traits play a meaningful role in learning and decrease performance and should consider in faculty members selection.
\end{abstract}

Keywords: Narcissism; superiority; paranoia; denial; performance

\section{INTRODUCTION}

Paying attention to the ranking of high education institutes is increased in recent two decades and it is attracted by many faculties, policymakers, governmental officials and mass media. Academic ranking causes that universities with higher performance have better chances in the world; hence, the competition among universities to be included among global 500 universities is condensed day by day. Such competition alerts universities more and causes that they continuously try to improve their academic standards. Some universities such as University of Tehran and Sharif University of Technology have also understood such sensitivity and can be a proper paradigm for other domestic universities. In the meantime, Iranian twenty - year outlook emphasizes on the fact that Iran will have the top ranking in the region by 2025. Certainly, achieving desired scientific status woes the efforts by faculties and academic prudent administrators. In this line, professors' personality traits as the fundamental pillar of knowledge generation and software movement are too important. The main aim of present paper is to identify professors' personality traits and their relations with academic 
performance. Studies show that individuals' personality traits have extraordinary impacts on their performance (Brick and Mont, 1991). It is expected that provided guidelines on the basis of traits identification help the acceleration of domestic science generation. The traits of faculties are also important since the performance of professors determines academic performance finally and such ranking is based on professors' deliverables (performance).

In 1883, ranking was started since the publishing of the first United States News and World Report (USNWR) which included annual ranking of the best US universities. Afterwards, several ranking systems were established in USA, UK and other countries.

Ranking systems use weighting and collecting approaches so that current data and information in academic level are collected in terms of some measures related to training and probing quality, each measure is weighted, these weighted measures are accumulated and finally a sequential ranking of universities is created. Existing ranking methods have many strengths and weaknesses but they generally cause that universities know their position in the world. Additionally, through competition, ranking methods impact on high education quality indirectly, provide public with important information and are considered as an effective mechanism to increase academic accountability.

University ranking should provide a healthy balance between global values and the local traits of cultures, communities and training systems. It should cause an international comparison and excellence seeking in international training space. For example, Shanghai Superior Training Institute ranked global universities in terms of academic performance to evaluate the gap between Chinese and global universities and conducted researches based on international comparable information. Finally, due to demands of many countries, in 2003, this group decided to publish its statistics in Internet (Academic Ranking World Universities or ARWA) which welcomed internationally since it has about 2000 visitors per day.

Table 1. Criteria and weights for the 2004 ARWU.

\begin{tabular}{|c|c|c|}
\hline Criterion & Indicator & Weight \\
\hline Quality of education & $\begin{array}{c}\text { Alumni of an institution winning } \\
\text { Nobel Prizes and Fields Medals }\end{array}$ & 10 \\
\hline \multirow{2}{*}{ Quality of faculty } & $\begin{array}{c}\text { Staff of an institution winning } \\
\text { Nobel Prizes and Fields Medals }\end{array}$ & 20 \\
\cline { 2 - 3 } & $\begin{array}{c}\text { Highly cited researchers in 21 } \\
\text { broad subject categories }\end{array}$ & 20 \\
\hline \multirow{2}{*}{ Research output } & Articles published in Nature and Science & 20 \\
\cline { 2 - 3 } & Articles Indexed in SCIE and/or SSCI \\
\hline Size of institution & Academic performance relative to \\
institutional size & 10 \\
\hline Total & 100 & 20 \\
\hline
\end{tabular}

Source: Cailiu and Cheng, 2005:128 
Table 2. Indicators and Weights Used in The Times Good University Guide 2005.

\begin{tabular}{|c|c|c|}
\hline University feature & Weight & Description \\
\hline Teaching & 2.5 & $\begin{array}{l}\text { University-wide average of Teacher Quality } \\
\text { Assessment scores in individual departments. } \\
\text { Maximum possible score is } 24 \text {. }\end{array}$ \\
\hline Research & 1.5 & $\begin{array}{l}\text { University-wide average of Research Assessment } \\
\text { Exercise scores in individual departments. }\end{array}$ \\
\hline Entry standards & 1 & $\begin{array}{c}\text { Average A-level score (or Scottish Higher score) of } \\
\text { new students under the age of } 21 . \text { Maximum } \\
\text { possible score is } 30 .\end{array}$ \\
\hline Student-to-staff ratio & 1 & $\begin{array}{c}\text { Number of student full-time equivalents (FTE) } \\
\text { divided by total } \\
\text { teaching FTE. }\end{array}$ \\
\hline $\begin{array}{l}\text { Library and computer } \\
\text { spending }\end{array}$ & 1 & $\begin{array}{l}\text { Spending on library staff and holdings and computer } \\
\text { hardware and software divided by student FTE. }\end{array}$ \\
\hline Facilities spending & 1 & Spending on facilities divided by student FTE. \\
\hline Percent high degrees & 1 & $\begin{array}{c}\text { Percentage of graduates achieving first and upper } \\
\text { second class } \\
\text { degrees. }\end{array}$ \\
\hline Graduate destinations & 1 & $\begin{array}{l}\text { Proportion of graduates that enter further study or a } \\
\text { graduate track job. }\end{array}$ \\
\hline Completion rate & 1 & $\begin{array}{c}\text { Length of time students take to complete degree } \\
\text { compared with length of time they would be } \\
\text { expected to study if they completed the course } \\
\text { normally. }\end{array}$ \\
\hline
\end{tabular}

Source: Guarino and Ridgeway, 2005:152

For any indicator, the scale of each university is 100 and other universities are computed as a percentage of higher scales. According to this institute, three superior universities in 2007 include: (1) Harvard, (2) Stanford and (3) California.

In addition to benchmarks to assess universities, there are also some measures to evaluate academic professors shown in Table 3. One should note that students and professors are two basic components of academic success and considering their important role in promoting academic performance will finally lead into university's status enhancement in international level.

By attracting competent persons and encouraging good trends will be equipped with an important tool to achieve excellence in high education (Cailio and Cheng, 2005) which is important in achieving overall development plans of the country because of the aims and special functions of high education system (Mohammadi et al, 2007). In the meantime, respecting academic performance to recognize and understand the realities and paving the ground to develop the actions especially policymakers are highly important (Naderi, 2008). 
Table 3. Items typically used for academic professors assessment in Japanese universities.

\begin{tabular}{|c|c|}
\hline Items & Categories \\
\hline Education & Systematization of faculty, graduate school, etc. \\
& Development/improvement of courses \\
Admission-related tasks
\end{tabular}

\section{NARCISSISM}

Narcissism roots in Greek Narcissus phrase which means extraordinary interest to self. Narcissism extends in an independent developmental trend from childhood to adulthood and appears in two normal and abnormal kinds. In normal kind, it leads into behaviors like creativity and innovations and in abnormal kind, it leads into behaviors like self - centrality, indefinite sensation to criticism, lack of sympathy with others, imagination, self - rendering, power image, unlimited power and using others to progress and promote (Rosenthal and Pitinsky, 2006: 621). Westen \& Tobacyk (997: 648-652) have summarized the narcissisms of personality specification based on six psychological and behavioral backgrounds:

Denial: Narcissist personality if often identified by denial of difference between ideal ego and real ego. By denial narcissist individuals are seeking for the rejection of accepting the responsibility of their mistakes. Otherwise they are attributed to them. In this case, the members towards organization outside credit have been sensitive and by revealing the information try to protect and promote them.

Rationalize: Individuals' Endeavour for justification or finding the reason of unacceptable behavior in the purpose of offer them in the form of acceptable.

Self-aggrandizement: it is induced to estimate the abilities and individuals' out come more than extent. For example staff of AT\& T tends to narrate the stories that indicate the 
manner of their treatment with immense fire. In this way, they exaggerate toward their ability encountering with accident and disaster.

Attributional egotism: such persons attribute favorite consequences to themselves (internal factors) while they attribute the un-favorite to the external factors.

Entitlement: The person forces other work for them and they consider it as their right. And they do not have the ability of sympathy with the senses of others. Lack of attention and sympathy of others with insatiable enthusiasms lead to others ' admiration and confirmation. The entailment specification leads to this case that narcissist persons think, they do not any mistake as a result they are not eager to forgive the others. (Brown 1997, 643-686). Researches indicate the positive outcome between narcissism and self - forgiving and the negative relationship and accepting sin.(Strelan 2007: 259-269).

Anxiety: The case that Narcissist individuals suffer from sense of depression, notworthy, self-illness.

Undoubtedly, managers are responsible for organizational failure or success. Since managers and university professors are key factors to promote academic performance, their decisions impact on organizational failure or success. Managers' decisions are impacted by their personality traits among which narcissism has destructive impacts on organizational decisions and can create organizational crisis. Sometimes, managers emphasize on their wrong decisions and spend paramount cost and time which generate problems for organization. Meanwhile, narcissism leads into a motivation for self - enhancing. Self enhancing motivation of narcissists could lead into success. However, it can lead into damaging effects. If the outcomes of performance are appreciated by rendering the special skills and capabilities would cause self - enhancing. Most people are somehow looking for self - enhancing but narcissists are very interested in personal glory. Since the mindset of narcissists is busy with self - enhancing, they should be more aware of some functional tasks which lead into more self - enhancing potentially. When narcissists understand that a task leaves no room for their self - enhancing, they lose their motivation and their performance will be hurt.

Better performance provides more chance for self - enhancing. Additionally, when the ideas of audiences were valued, the chance of self - enhancing will be higher than when the performance is observed by those people whom individual does not respect. Finally, performance should have the trait of a special success in order to have self - enhancing characteristic. The first factor is clear. The value of performance self - enhancing increases with performance quality and the person achieves no honor with low level performance. A revealed performance is further self - enhancing than a hidden performance even though high performance in the attendance of respected audiences does not necessarily leads into self enhancing. When the success of a work is assumed obviously or expected, it is not considered as the determinant of prosperity. So, challenging tasks are more self - enhancingal than unchallenging tasks (Wallas, 2001: 4).

The impact of challenge level in the performance of narcissistic professors is also important. When the aim of a work is recognized as a difficult challenge which people achieve it rarely, narcissists should use it as an excellent opportunity to show their superiority to others. As the mindset of myth Narcissus was busy to its reflected beauty, modern narcissists also look for their reflected greatness and superiority in seeking for opportunities. As discussed earlier, achieving hard aims is considered as a trait of extraordinary capabilities more than achieving easy aims. The motivation of narcissists in achieving hard aims is due to their more interest in self - enhancing than many other persons. In addition, high introspection of narcissists gives them a trust by which they can be successful in many affairs 
that other people have failed. The combination of high motivation and high confidence helps their performance in challenging tasks. In contrast, high performance in unchallenging works dose show high capability. Therefore, narcissists have low motivation to obtain the aims of an unchallenging performance. High self - expectation of narcissists can have a destructive effect on performing their unchallenging tasks (Wallas, 2001: 7). A level of narcissism is natural for all professors.

Narcissistic professors may act successfully and their attendance may be necessary in university. When strategists and risk - takers are smart, they stimulate others and move university toward a merit future. Contradictorily, they may involve in angriness and self rendering which can destroy the university (Maccoby, 2004: 67). There are also many opportunities in researches and studies for persons' self - enhancing via their performance and includes situations which create recognition, prestige or other benefits like speeches, etc. Such opportunities are attractive for the self - enhancing of narcissists who want to be fascinated. Such situations provide individuals with opportunities to show high performance against their counterparts. Tendency to success is an inner part of value system of such persons and when incapability in achieving a desired success level threats their success; they commit false actions to achieve a desired result. Their desired result may be promotion and assignment in a selected organization or achieving honors and famous, award or research scholarship. Therefore, such persons are looking famous and self - rendering to achieve power. When an organizational structure poses the behavior and opportunities of self enhancing, undoubtedly narcissists who are involved in self - enhancing are attracted by such opportunities. In an academic campus, narcissists may turn around ethical principles due to their self - priority sense, paying attention to unlimited success and competent sense in performing researches in order to obtain complete advantage of famous and respect chances (Davis et al, 2008: 202).

Usually, narcissistic professors have no ground for learning errors. Learning from errors is a process by which people (1) emphasize on committed errors, (2) find the roots, (3) develop knowledge on outcome - performance relationship and evaluate its effects on workplace, (4) employ this knowledge to mitigate or improve the behavior and decision making. By this attitude, learning from errors is an action which involves objective thinking, error analysis and new knowledge utilization in decisions and activities. The consequences of learning from errors are an understanding and view which may improve the skills and capabilities of a person to find and remedy errors and to mitigate the possibility of committing them again (Zao, 2007: 19-21). Besides, narcissistic professors tend to resign when they face with failure or negative feedback. They prefer to look for less challenging works in order that their performance evaluated desired and they prefer to escape when think that their performance may be evaluated negatively. Finally, they value learning from thinking and error analysis with less possibility (Zao, 2007: 21).

Since the population of the research includes domestic universities and high education system, universities are considered in clarifying organizational narcissism and professors are considered in clarifying individual narcissism. Organizational narcissism is organizational existence which tends to improve and promote its legitimacy by its agents and sees itself as the only active agent in social changing process. Organizational narcissism is the result of organizational demand for legitimacy. Obviously, the existence of narcissistic organization prefers legitimacy to accountability since such organization considers the rightness of its existence more than well servicing (Ganesh, 2003: 558). A narcissistic university has false imaginations of success and greatness. Any problems are attributed to external situations that are out of individuals' control. The leaders of such organizations are drawn as genius and all 
their actions or speeches are reported enthusiastically. Many failures and strategic mistakes are happened in narcissistic organizations.

In studying individual narcissism (academic professors in this research), several traits are mentioned for narcissistic professors including: narcissistic professors may operate successfully and their attendance in university may be necessary. When they are smart strategists and risk-takers, they stimulate others and move the university toward a merit future. Contradictorily, they may involve in angriness and self - rendering which can destroy the university (Maccoby, 2004: 67). Narcissistic professors exaggerate their successes and talents and they are proud. They believe that they are special and are not understood by others unless by a group of talented persons with high position. They daydream on their successes, power and capabilities and compare themselves with famous persons. They demand permanent consideration and appreciation, they expect favor and ideal behavior in any condition, they often talk about themselves, they often use "I", they are not able to have sympathy with students' needs and feelings, they often envy, they believe that other also envy, they show that they are patient while they are proud, they show high confidence and self - esteem, they refuse or neglect the truth, they do not trust others, they attack those persons who ask about their decisions or criticize, they relate to those students whom they think that they can progress them to achieve their aims and self - esteem, they exploit such students and they have problems in team working (Chatterjee and Hambrick, 2007). By considering above traits for narcissistic professors, one can conclude that professors' narcissism decreases their performance level and finally mitigates the ranking of their university among other universities. This issue is provided in eight hypothesis.

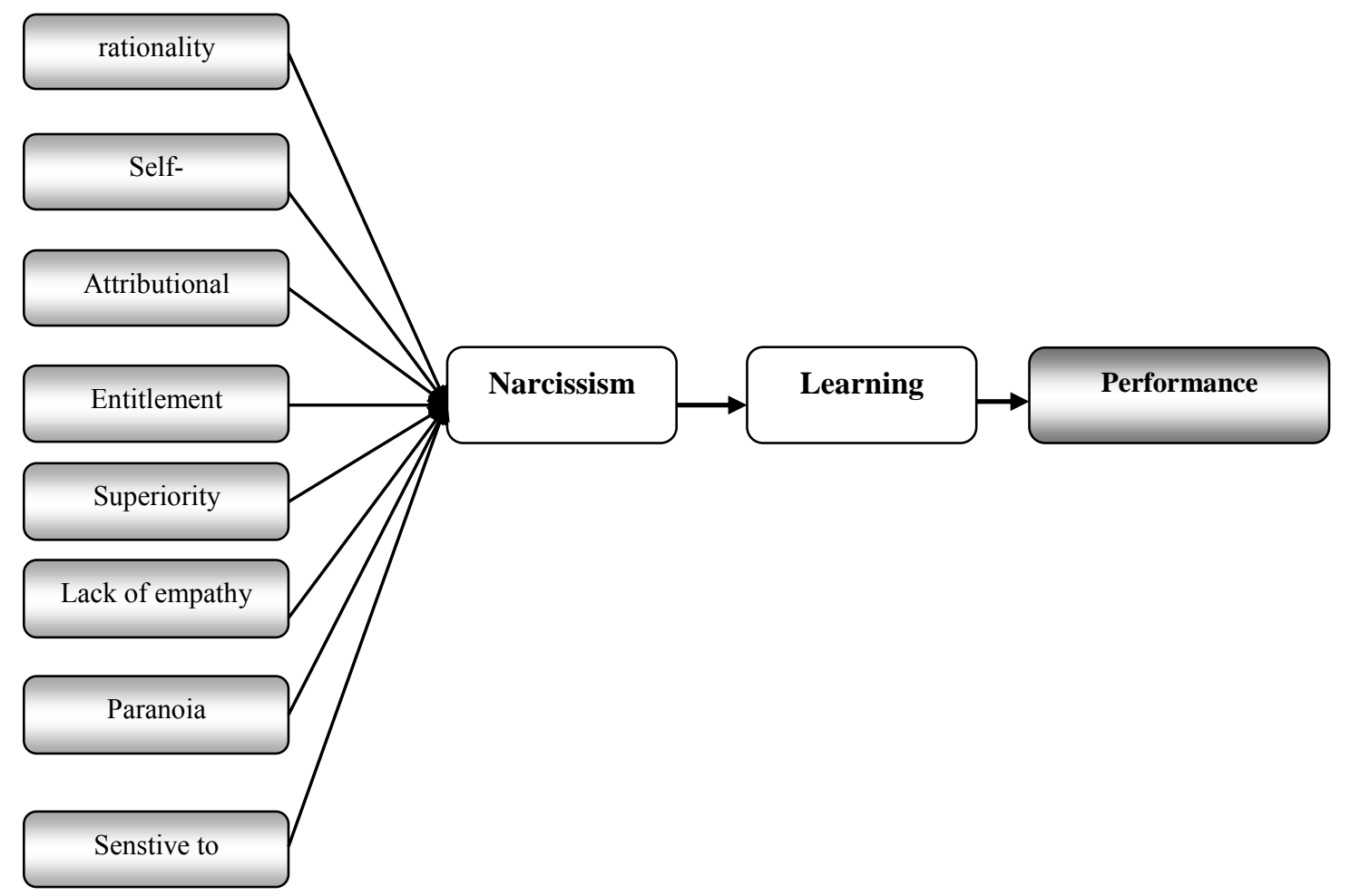

Figure 1. Research conceptual model. 


\section{Hypotheses:}

H1: Rationality of faculty members impact on the performance of professors through impact on their propensity to learning.

H2: Self-aggrandizement of faculty members impact on the performance of professors through impact on their propensity to learning.

H3: Attributional egotism of faculty members impact on the performance of professors through impact on their propensity to learning.

H4: Entitlement of faculty members impact on the performance of professors through impact on their propensity to learning.

H5: Superiority of faculty members impact on the performance of professors through impact on their propensity to learning.

H6: Lack of empathy of faculty members impact on the performance of professors through impact on their propensity to learning.

H7: Paranoia of faculty members impact on the performance of professors through impact on their propensity to learning.

H8: Senstive to criticism of faculty members impact on the performance of professors through impact on their propensity to learning.

\section{METHODOLOGY}

In terms of aims, present research is an applied one and it is descriptive (non-testing) in terms of data collection. It is also a field study while it is casual in terms of relations between variables. Job performance is dependent variable and narcissism is independent variable. Statistical population consists of administrators and professors of Tehran universities. Sampling method was simple random among faculties (10 superior university, 30 individuals in each university). The volume of statistical population was estimated as 300 individuals. The main tool to collect data was questionnaire. The questionnaire included 56 items designed by Likert five - scale range as (5) absolutly agree, (4) agree, (3) no idea, (2) disagree and (1) absolutly disagree. The alpha ratio of narcissism is $81 \%$ (based on Roskin and Hall standard questionnaire, 1979) with 23 items. There are 8 items for propensity to learning (based on Michael Maquart Zali, 2006) and 5 items for performance like the number of books, scientific papers, ISI, other papers and research contracts in past five - years with industry and organizations and the number of guided thesis.

In the meantime, to measure the validity of questions, content and factor credit were used. To measure the content credit, the ideas of connoisseurs, academic professors and experts were used. In this step, by conducting various interviews and obtaining the ideas of different people, reforms were made and it became certain that the questionnaire measures the considered traits of researchers. Testing the factor credit of questionnaire was confirmed by a factor analysis. 


\section{RESEARCH FINDINGS}

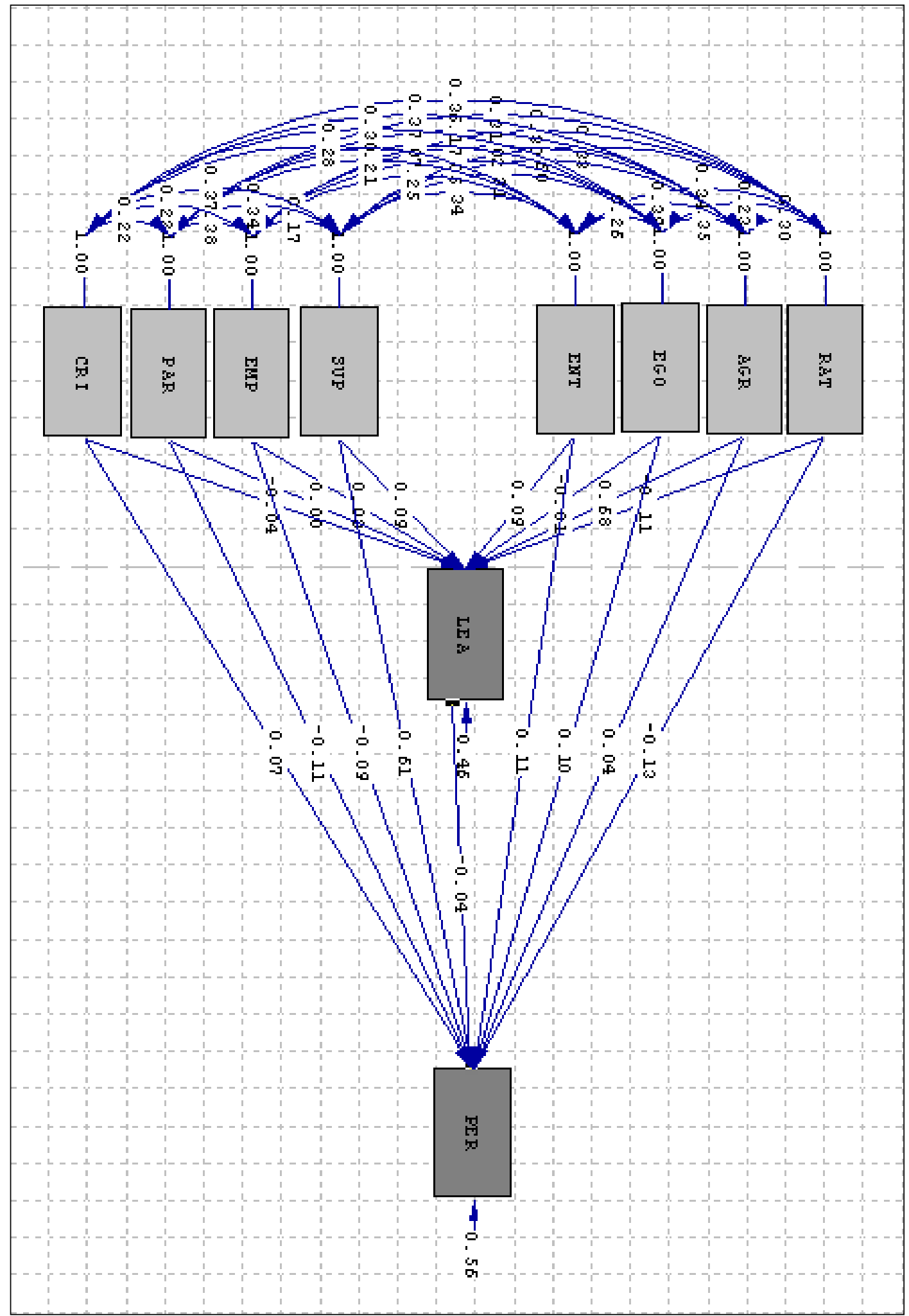

Figure 2. Structural equations model (standardized ratios). 


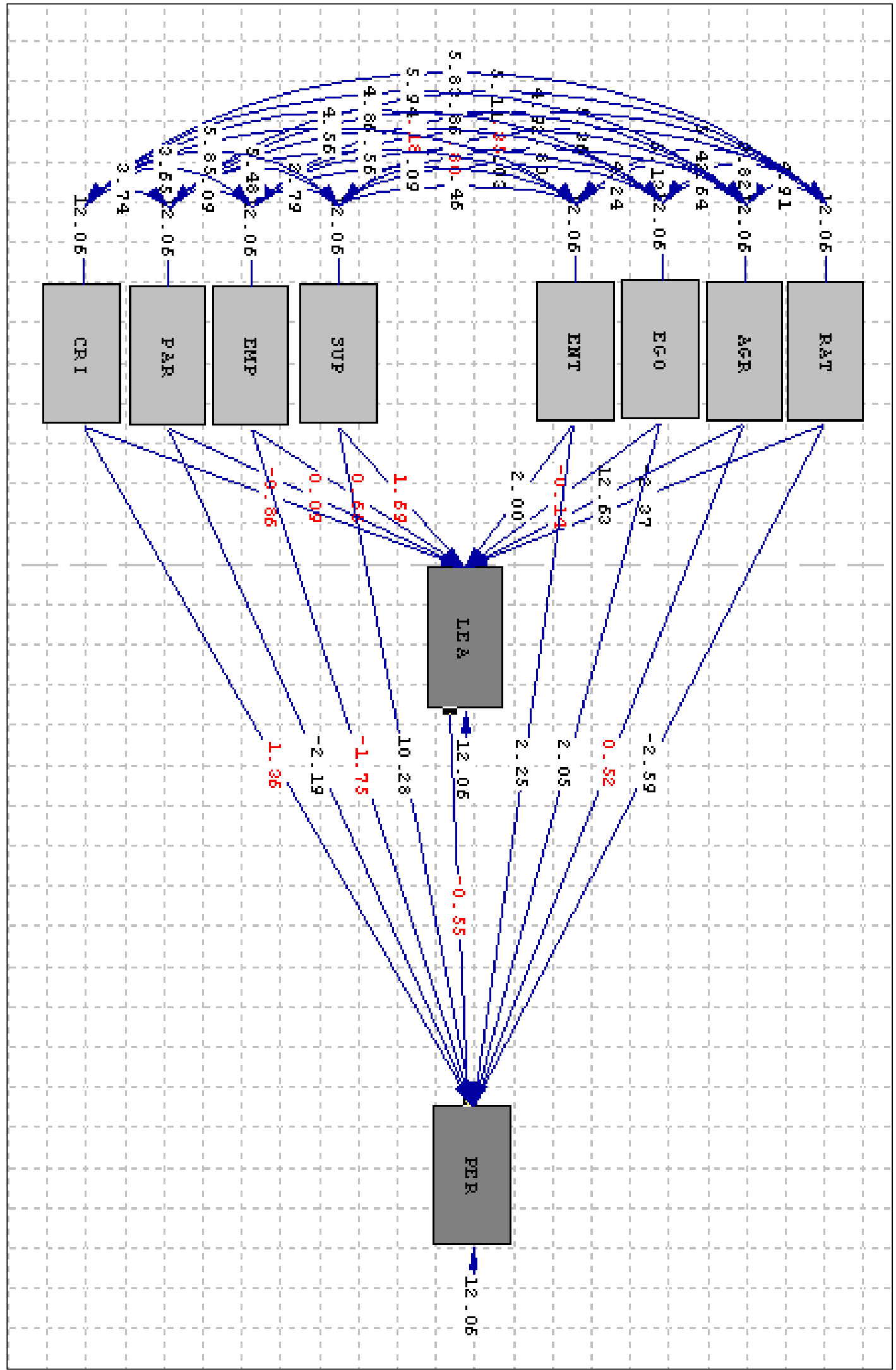

Figure 3. Structural equations model (significance). 
PER $=$ Professors' performance, $\mathrm{LEA}=$ propensity to learning, $\mathrm{RAT}=$ rationality, AGR $=$ Self-aggrandizement, $\mathrm{EGO}=$ egotism, $\mathrm{ENT}=$ Entitlement, $\mathrm{SUP}=$ Superiority, $\mathrm{EMP}=$ Lack of empathy, $\mathrm{PAR}=$ Paranoia, $\mathrm{CRI}=$ Senstive to criticism.

To test hypotheses, initially Spearman's ranked correlation test was used along with SPSS 15 software to measure the correlation between variables. To investigate the existence of relationship and its extreme between two variables, correlation test was used.

The casual relationship between dependent and independent variables by using structural equations model - making were tested by Lisrel 8.53 software. While structural equations model - making is the final step in factor analysis, it emphasized on previous confirmation of research measurement scales. Through fitting model indices, following conceptual model is shown.

\section{DISCUSSION AND CONCLUSIONS}

The results show worrying implies. The relationship between propensity to learning of professors and their performance is insignificant. These ratios show a scientific crisis in future namely there is no significant relationship between professors' propensity to learning and their deliverables. Also this research shows that narcissism decrease performance that is an alarm and should be considered by managers in professors selection.

As previous researches show (Wallas, 2001), narcissistic persons justify realities proportionate to their demands. They learn lessons from their failures less. In universities, professors impact their performance by legitimizing their acts and decisions and finally justify their responsibility. In such conditions, narcissistic professors are permanently legitimize their works and try to rationalize their unacceptable works. For example, a professor or administrator who is indifferent to the questions of students or counterparts and try to pose his/her even wrong ideas, tries in anyway to accept his/rationality to them. Such trait mitigates learning and finally reduces performance since the main concern of such persons is to legitimize the mistakes and failures; so they have lower tendency to learning and dedicate lower time which is seen in poor performance. Certainly, such weak performance causes the weak performance of the group, college and university and, finally, university will not enjoy an acceptable status in national and international levels.

Universities (college groups) use annual reports to pretend the guilty to undesired results and attribute positive results to them which impact on performance. In previous researches (Davis et al, 2008: 202), it was shown that such persons accept no responsibility for problems and, instead, put the responsibility to others. For example, a professor who consider him/her as a determinant component in university and believes that his/her decisions play important role in achieving academic aims, undoubtedly tries to improve the performance. Although the research indicated no relationship between this trait and learning. Narcissistic professors listen to information that they demand and do no learn from others easily. They also do not accept any criticism. Research findings did not show a significant relationship between this trait and performance since one of the main indicators of performance improvement and change is to accept the criticism and reform. When our administrators and professors do not accept criticism and do not make reforms, we can not observe changes in performance. For example, we should not expect changes in the performance of administrators and professors who insist their wrong beliefs and do not value what students and their counterparts say. Noteworthy, this trait had higher average in lower 
ranking universities. As the result shows, another item for narcissism is paranoia that has a negative impact on performance too because in this situation professor are pessimistic and don't trust their colleagues and students thus they can't focus on duties and can't do teamwork and this trait influences their performance.

According to findings of this research, university administrators are recommended to:

1. Conduct psychological tests before employing professors to prevent narcissism impacts.

2. Revise professors' performance assessment and do not only pay attention to quantity.

3. Determine the relationship between professors' performance and ranking benchmarks.

4. Determine the materials should be learnt.

\section{References}

[1] Amernic J., Russel J. (2007). "Guidelines for CEO speak:editing the language of corporate leadership". Strategy and Leadership, 35(3), 25-3.

[2] Boyett and Associates, (2006). "surviving the destructive narcissistic leaders". Adminstrative Science Quarterly, Vol. 48.

[3] Brown A. (1997). "Narcissism, identity and legitimacy". Academy of Management Review, 22(3), 643-686.

[4] Cailiu Nand Cheng Y. (2005). "the academic Ranking of World Universities". Journal of Higher Education in Europe, 30(2).

[5] Campbell W.K., Goodie, A.S. Foster J.D. (2004). "Narcissism, confidence, and risk attitude". Journal of Behavioral Decision Making, 17: 297-311.

[6] Chatterjee A., Hambrick D. (2007). "Narcissistic chief Executive officers and their effects on company strategy and performance". Adminstrative Science Quarterly, 52: 351-386

[7] Corsini R. J. (2002). The Dictionary of Psychology, New York: Brunner-Routledge.

[8] Davis M., Wester K., King B. (2008). "Narcissism, Entittlement and Questionable Research practice in counseling: A poilot study". Journal of Counseling and Development, 86.

[9] Freud S. (1914). "On narcissism: an introduction in freuds". Collected Papers. Vol. 4 basic books, New York. NY, pp: 30-59.

[10] Ganesh S.H. (2003). “Organizational Narcissism”. Management Communication Quarterly, 34: 558.

[11] Glad B. (2002). "Why tyrants go too far: Malignant narcissism and absolute power". Political Psychology, 23: 1-37.

[12] Guarino C., Ridgeway G., Chun M., Buddin R. (2005). “A new approach to university Rankings Using Latent Variable Analysis". Analysis, Higher Education in Europe, 30: 147-165.

[13] Holian R. (2006). "Management decision making ethical issue and Emotional intelligent”. Leadership and Development Journal, 44(8), 1122-1138. 
[14] Kets de Vries M., and Balazs K. (2004). "Greed, vanity, and the grandiosity of the CEO character". In R. Grandossy (Ed.), Leadership Governance from the Inside out, (pp. 51-61). New York: John Wiley.

[15] King J. (2003). "Perfectionism in Leadership: Exploring the link between Leader SelfEsteem, Leader Self-Efficacy, Leader Narcissism and Perfectionism". A Dissertation Submitted to the Faculty of Regent University School of Leadership Studies.

[16] Kramer R.M. (2003). “The harder they fall”. Harvard Business Review, 44: 58-66.

[17] Lubit R. (2002). “The Long-Term Organizational Impact of Destructively Narcissistic Managers". Academy of Management Executive, 16(1), 127-138.

[18] Lynn Rapier M. (2005). "an interview study of narcissistic executives: piercing the corporate veil of narcissism in the workplace". A dissertation presented to the Faculty of Saybrook Graduate School and Research Center.

[19] Maccoby M. (2004). "The productive narcissist: The promise and peril of visionary leadership". New York: Broadway Books.

[20] Miller J., Martinez M., Reidy D. (2008). "Narcissism and aggression: Effects of positive, negative and delayed feedback, Personality and Individual differences". Journal of Research in Personality, 44: 140-149 .

[21] Rosenthal S., Pittinsky T. (2006). "Narcissistic Leadership", The Leadership Quarterly, 17: 617-63.

[22] Stein M. (2003). "Unbunded irrationality: Risk and Organizational Narcissism at Long Term Capital management". Human Relation, 31: 523.

[23] Strelan P. (2007). "Who forgives others, themselves and situation? The roles of narcissism, guilt, self-esteem and agreeableness, Personality and Individual differences". Journal of Research in Personality, 42; 259-269.

[24] Vogel C. (2006). “A field guide to narcissism”. Psychology Today, 39(1), 68-73.

[25] Wallace H. (2001). "Narcissisn and Performance". Submitted in partial fulfillment of the requirements for the degree of Doctor of philosophy.

[26] Wesner B. (2007). "Responding to the workplace Narcissist". B.A. Thesis.

[27] Wonnerberg D. (2007). "The nature of Narcissism within Organizational Leadership". $\mathrm{PhD}$. Thesis.

[28] Barick M. R., Mount. M. K. (1991). "The Big-Five personality dimensions in job performance: A meta-analysis". Personnel Psychology, 44, 1-26. 